\title{
Isolated Neutral [4]Helicene Radical Provides Insight into Consecutive Two-Photon Excitation Photocatalysis
}

\author{
Aslam C. Shaikh, ${ }^{a}$ Md Mubarak Hossain, ${ }^{a}$ Ramandeep Kaur, ${ }^{a}$ Jules Moutet, ${ }^{a}$ Anshu Kumar, \\ Benjamin Thompson, ${ }^{\mathrm{c}}$ Vanessa Huxter, ${ }^{\mathrm{b}}$ and Thomas L. Gianetti ${ }^{\mathrm{a} *}$ \\ ${ }^{a}$ Department of Chemistry and Biochemistry, University of Arizona, Tucson, AZ 85721, United States. \\ bepartment of Chemistry and Department of Physics, University of Arizona, Tucson, AZ 85721, United States. \\ 'Department of Optical Sciences, University of Arizona, Tucson, AZ 85721, United States.
}

\begin{abstract}
Direct activation of strong bonds in readily available, benchtop substrates offer a straightforward simplification, albeit in most cases existing catalytic systems are limited to unlock such activation. In recent years, a surge of in-situ generated organic radicals that can act as potent photoinduced electron transfer (PET) agents have proved to be a powerful manifold for the activation of remarkably stable bonds. Herein we document the use of $N, N^{\prime}$-di- $n$-propyl-1,13-dimethoxyquinacridine ( $\left.{ }^{n} \mathrm{Pr}-\mathrm{DMQA}{ }^{*}\right)$, an isolated and stable neutral helicene radical, as a highly photoreducing species. This isolable doublet state open shell radical offers a unique opportunity to shed light on the mechanism behind PET reactions of organic radicals. Experimental and spectroscopic studies revealed that this doublet radical has a long lifetime of $4.6 \pm 0.2 \mathrm{~ns}$, an estimated excited state oxidation potential of $-3.31 \mathrm{~V}$ vs SCE, and can undergoes PET with organic substrates. The strongly photoreducing nature of the ${ }^{n} \mathrm{Pr}-\mathrm{DMQA}{ }^{*}$ was experimentally confirmed by the demonstration of photo activation of electron rich aryl bromides and chlorides. We further demonstrated that ${ }^{n} \mathrm{Pr}-\mathrm{DMQA}{ }^{*}$ can be photochemically generated from its cation analog $\left({ }^{n} \mathrm{Pr}-\mathrm{DMQA}{ }^{+}\right)$ allowing catalytic functionalization of aryl halide via a consecutive photoexcitation mechanism (ConPET). Dehalogenation, photo-Arbuzov, photo-borylation and C-C bond formation reactions with aryl chlorides and bromides are reported herein, as well as the $\alpha$-arylation of carbonyl using cyclic ketones. The latter transformation exhibits the facile synthesis of $\alpha$-arylated cyclic ketones as critical feedstock chemical for diverse useful molecules, especially in the biomedical enterprises.
\end{abstract}

\section{Table of Content:}

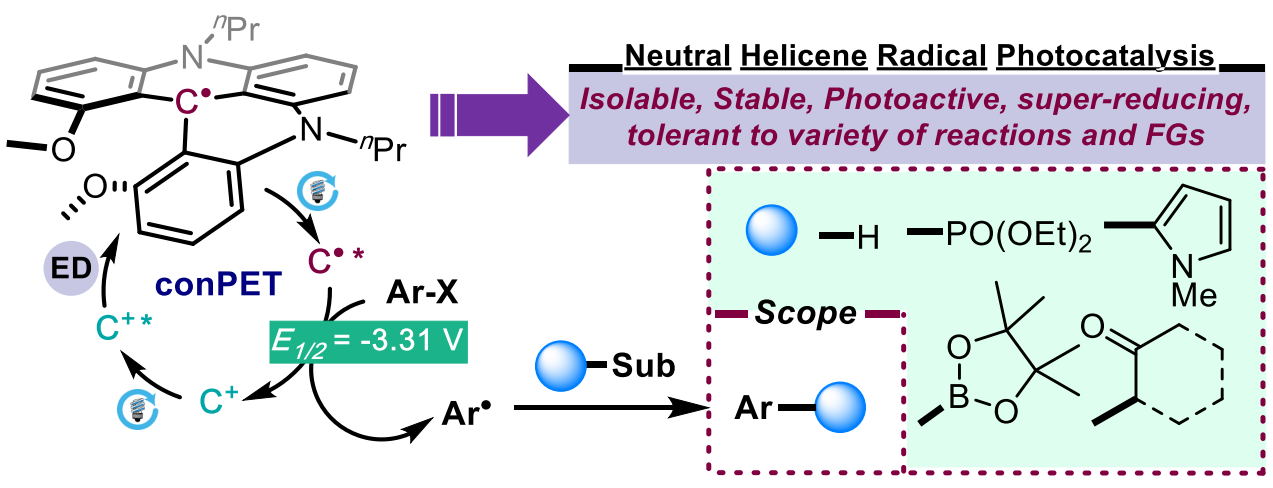




\section{INTRODUCTION}

Over the past decade, photoredox catalysis has received a fast and growing interest from the world of synthetic chemistry. ${ }^{1}$ By combining visible light with a photocatalyst (PC), a large variety of efficient and selective transformations have been achieved under mild conditions, during which the excited state PC is involved in a single electron transfer (SET) with a substrate or a co-catalyst. However, SET with conventional photocatalyst is usually limited to reduction potential down to $-2.0 \mathrm{~V}$ vs. Saturated Calomel electrode (SCE). ${ }^{2}$ In recent years, several elegant reports have shown that open shell doublet radicals, generated in-situ, either electrochemically ${ }^{3}$ or photochemically, can act as potent photoreducing agents. ${ }^{4}$ For example, a two-photon excitation process, commonly purported as consecutive photoelectron transfer (conPET) pathway, is proposed as the photochemical generation pathway of potent photoreducing organic radicals (Figure 1a, left). ${ }^{5}$ In that process, the excited state of a close shell single photocatalyst PC* (neutral or cationic) is generated upon the first excitation. Then, a sacrificial electron donor can act as a reductant and participate in SET with $\mathrm{PC}^{*}$ to generate $\mathrm{PC}^{\bullet}$ radicals (anionic or neutral). A second successive photoexcitation generates the radical excited state $\mathrm{PC}^{\bullet *}$ that can act as super photoreducing agent $\left(\mathrm{E}_{1 / 2}{ }^{\mathrm{red} *}\right.$ $=-2.3$ to $-3.4 \mathrm{~V}$ vs SCE) (Figure 1a). ${ }^{6}$ This concept of two-photon excitation process has been reported with numerous notable photocatalysts such as PDI, ${ }^{7}$ DCA, ${ }^{8}$ anthraquinone, ${ }^{9}$ Rhodamine $6 \mathrm{G},{ }^{10}$ benzo[ghi]perylene (BPI), ${ }^{11}$ 4-DPAIPN, ${ }^{12}$ 3-CzEPAIPN, ${ }^{13}$ Mes-Acr, ${ }^{14}$ and Deazaflavin ${ }^{15}$ (Figure 1b). As a common benchmark reaction, photoredox $\mathrm{C}\left(\mathrm{sp}^{2}\right)$-X bond activation in aryl bromides and chlorides, Birch reduction, and sulfonamide cleavage showcased the extreme photoreducing ability of radical photocatalysts in most cases. Despite these convincing reports, an intriguing aspect of photoactive open shell doublet radicals generated in-situ is that alternative mechanisms cannot be completely ruled out. For example, Leonori et. al. recently reported that $\alpha$-aminoalkyl radical, generated via SET between alkyl amines and a close shell excited PC*, can initiate halogen atom transfer (XAT) (Figure 1a, right). ${ }^{16,17}$ Therefore, the concept of super photoreducing radicals in conPET systems is weakened due to the common usage of amine as the sacrificial electron donor. Furthermore, a recent study by Nocera and colleagues questioned the viability for radicals generated in-situ during conPET or electrophotocatalysis to act as efficient photocatalysts, due to their short-lived excited state which should hamper their participation in bimolecular reactions with substrates. They concluded that, instead, a close shell singlet species, such as a Meisenheimer complex or side product impurities, formed from the reactive open shell doublet radical can act as the super reducing photoreagent (Figure 1a, top). ${ }^{18}$ To date, stable and isolatable radicals able to undergo photoinduced electron transfer during an organic transformation remain elusive. Therefore, the synthesis and isolation of such photoactive organic radicals are of great interest in order to shed light on the ability for open shell doublet species to act as photoreducing agents.

As part of our ongoing interest in the photochemical properties of the helical carbenium system, we recently reported the use of $N, N^{\prime}$-di-n-propyl-1,13-dimethoxyquinacridinium $\left({ }^{n} \mathrm{Pr}-\mathrm{DMQA}^{+}\right)$tetrafluoroborate ${ }^{19}$ as an organic photoredox catalyst for photoreductions and photooxidations under red light $\left(\lambda_{\max }=640 \mathrm{~nm}\right){ }^{20}$ Several fundamental organic transformations involving either oxidative quenching or reductive quenching pathways have been demonstrated. During these studies, we identified the neutral helicene radical $\left({ }^{n} \operatorname{Pr}-\right.$ $\mathrm{DMQA}^{*}$ ) as a possible radical intermediate in the reductive quenching photocycle. In our contemporary studies, we reported the chemical synthesis, isolation, and characterization of ${ }^{n} \mathrm{Pr}-\mathrm{DMQA}{ }^{\circ}$ as part of a family of neutral quinolinoacridine radicals from their quinolinoacridinium cation analogs. ${ }^{21,22}$ Our studies showed that these radicals are highly persistent in their solid form as well as in solution for several months under inert conditions, and reversibly oxidize back to the cation upon exposure to air. 
We now report that the stable helicene radical ${ }^{n} \mathrm{Pr}-\mathrm{DMQA}$, first observed by Larsen et. $a l .{ }^{22}$ and isolated by our group, ${ }^{21}$ is a highly photoactive species with strong absorptions of light in the visible region. The excited state oxidation potential of this helicene radical has been estimated to be $-3.31 \mathrm{~V}$ vs SCE which makes it one of the strongest photoreductants. This radical can be made on gram scale, isolated, purified and stored in a glovebox, which allowed us to investigate its photophysical and photochemical properties, as well as its ability to act as a strong photoreducing agent without questioning the involvement of impurities or side products. Furthermore, the closed shell cation counterpart, ${ }^{n} \mathrm{Pr}-\mathrm{DMQA}^{+}$, is photoactive in red light, while ${ }^{n} \operatorname{Pr}-\mathrm{DMQA}^{*}$ is not, which offers a unique opportunity to probe the mechanism for the photoactivation of aryl bromides and chlorides under blue light excitation.

a Photocatalytic pathways of $\mathrm{C}\left(\mathrm{sp}^{2}\right)-\mathrm{X}$ bond activation

conPET or XAT or closed shell species

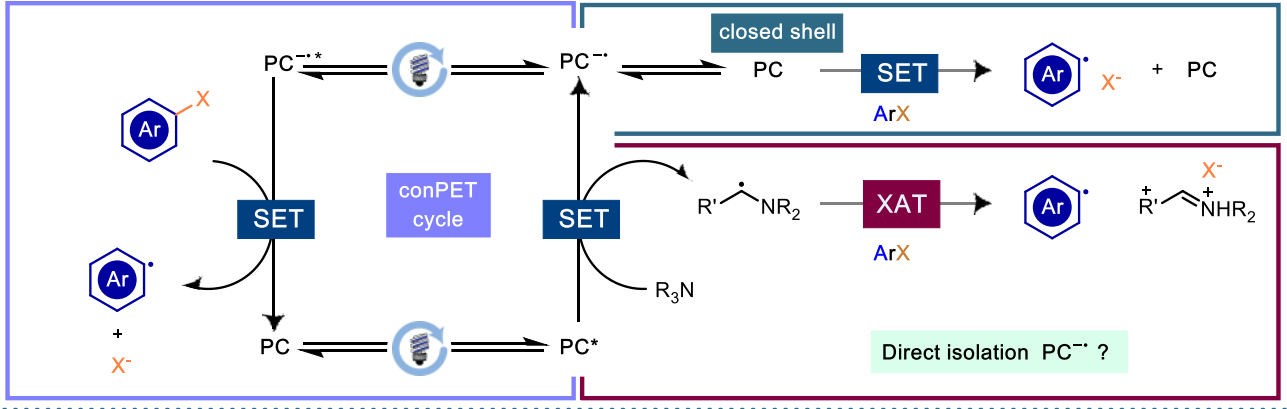

b Examples of transient anionic/neutral radical photocatalysts

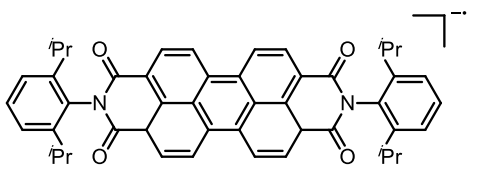

$\mathrm{PDI}^{-}$

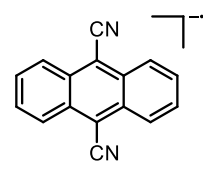

$\mathrm{DCA}^{-}$

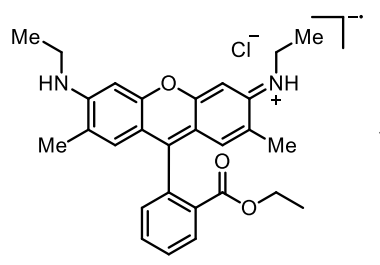

Rhodamine $6 G^{*}$

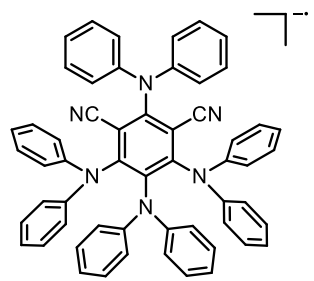

4-DPAIPN ${ }^{-}$
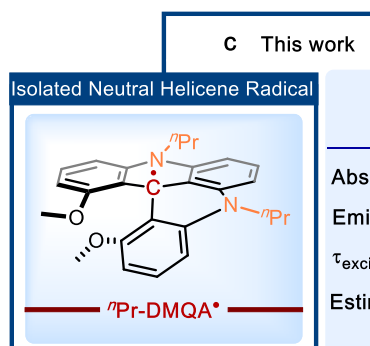

Photochemical Properties
of ${ }^{n} \mathrm{Pr}$-DMQA radical

Absorption maxima $392 \mathrm{~nm}, 440 \mathrm{~nm}, 467 \mathrm{~nm}, 557 \mathrm{~nm}$

Emission maxima $593 \mathrm{~nm}$

$\tau_{\text {excited state life time }} \quad 4.6 \pm 0.2 \mathrm{~ns}$

Estimated $E_{1 / 2}{ }^{*}$ ox

$-3.03 \vee$ vs SCE $\left(\lambda_{\text {ex }} 557 \mathrm{~nm}\right)$

$-3.31 \vee$ vs SCE $\left(\lambda_{\text {ex }} 440 \mathrm{~nm}\right)$

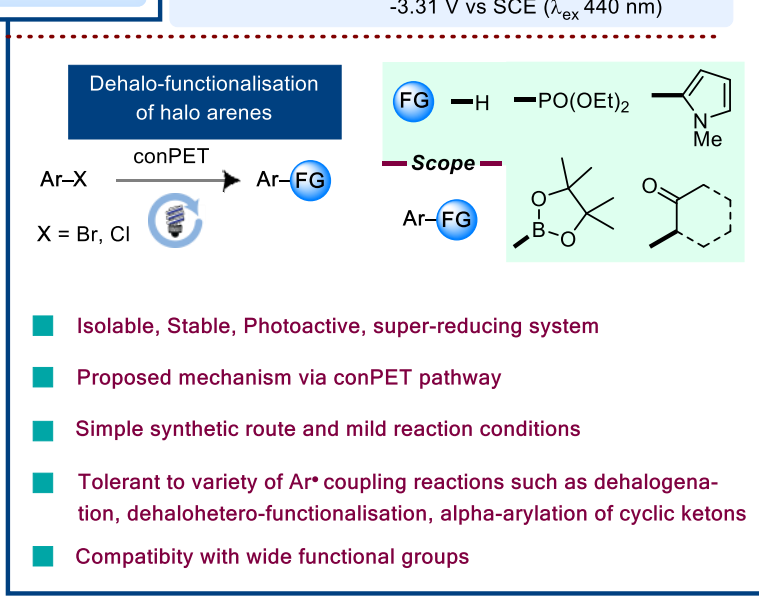

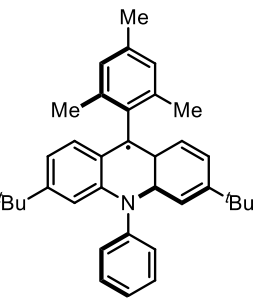

Mes-Acr ${ }^{\circ}$

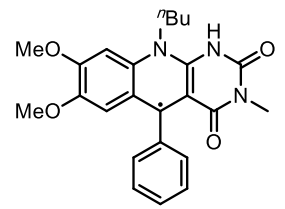

Deazaflavin<smiles>O=C1c2cccc(O)c2C(=O)C2C(O)=CC=CC12</smiles>

$\mathrm{Aq}-\mathrm{OH}^{\cdot-}$

Figure 1: Organic radicals as photocatalyst to activate $\mathbf{C}\left(\mathbf{s p}^{2}\right)-\mathrm{X}$ bond in aryl halides. a, Mechanistic pathways in photoredox catalysis for $\mathrm{C}\left(\mathrm{sp}^{2}\right)$-X bond activation. $\mathbf{b}$, Representative examples of transient organic radicals (neutral and anionic) as extremely reducing photocatalysts. c, This work isolated ${ }^{n} \operatorname{Pr}-$ DMQA radical. 


\section{RESULTS AND DISCUSSION}

Photophysical properties of ${ }^{n} \mathrm{Pr}-\mathrm{DMQA} \cdot$ radical. We recently reported that the chemical reduction of ${ }^{n} \mathrm{Pr}-$ $\mathrm{DMQA}^{+}$allows the synthesis and isolation of the stable double state organic radical ${ }^{n} \mathrm{Pr}-\mathrm{DMQA}{ }^{*}{ }^{21}$ Interestingly this radical was found to possess strong absorption of light in the visible region (391 nm, 440 $\mathrm{nm}, 467 \mathrm{~nm}$, and $557 \mathrm{~nm}$ ) and exhibits emission maxima at $593 \mathrm{~nm}$ (Figure 2a, and Figure S1 - S3). The life-time of the excited state was determined using time correlated single photon counting (TCSPC, see Supporting information). Excitation of ${ }^{n} \mathrm{Pr}$-DMQA ${ }^{*}$ resulted in a strong emission band characteristic of ${ }^{n} \mathrm{Pr}$ DMQA $^{*}\left(\lambda_{\max } \mathrm{em}=593 \mathrm{~nm}\right)$ whose average lifetime $(\tau)$ was measured to be $4.6 \pm 0.2 \mathrm{~ns}$ (Figure $\mathbf{2 b}$, and Figure S5 - S9) ${ }^{23}$ Interestingly, the fluorescence lifetime of the open shell doublet radical was found to be longer than its singlet cation analog $\left(5.7 \mathrm{~ns}\right.$ for $\left.{ }^{n} \mathrm{Pr}-\mathrm{DMQA}^{+*}\right) .{ }^{24}$ A multi nanosecond scale excited state lifetime is suitable for bimolecular electron transfer suggesting that the doublet neutral radical ${ }^{n} \operatorname{Pr}-\mathrm{DMQA}{ }^{*}$ could act as an effective PET agent. ${ }^{25}$ As previously oberved, ${ }^{20 d,}{ }^{21}$ the cyclic voltammogram of the ${ }^{n} \mathrm{Pr}-$ DMQA scaffold in acetonitrile revealed the presence of two reversible events, $E_{1 / 2}\left({ }^{n} \operatorname{Pr}-\mathrm{DMQA}^{++\bullet} /{ }^{n} \mathrm{Pr}-\right.$ $\left.\mathrm{DMQA}^{+}\right)=+1.27 \mathrm{~V}$ and $E_{1 / 2}\left({ }^{n} \mathrm{Pr}-\mathrm{DMQA}^{+} /{ }^{n} \mathrm{Pr}-\mathrm{DMQA}^{*}\right)=-0.85 \mathrm{~V}$ vs SCE when recorded between -1.5 $\mathrm{V}$ and $+1.5 \mathrm{~V}$ vs. SCE (Figure 2c, i) trace). However, when the potential window is extended to reach $2.0 \mathrm{~V}$ vs. SCE, an irreversible event at $E_{1 / 2}\left({ }^{n} \mathrm{Pr}-\mathrm{DMQA} /{ }^{n} \mathrm{Pr}-\mathrm{DMQA}^{-}\right)=-1.84 \mathrm{~V}$ vs SCE is observed, which then triggers the generation of an intermediate with an irreversible event at +0.67 V vs SCE (Figure 2c, ii) trace). Laursen et. al. have previously assigned this intermediate as the neutral close shell singlet ${ }^{n} \mathrm{Pr}-$ DMQA-H, which forms by reaction between acetonitrile and the highly reactive ${ }^{n} \mathrm{Pr}-\mathrm{DMQA}$. Based on the electrochemical and photophysical properties of ${ }^{n} \operatorname{Pr}-\mathrm{DMQA}^{*}\left(E_{1 / 2}{ }^{o x}\left(\mathrm{C}^{+} / \mathrm{C}^{*}\right)=-0.85 \mathrm{~V}\right.$ vs SCE,$E_{1 / 2}{ }^{\text {red }}\left(\mathrm{C}^{*} / \mathrm{C}^{-}\right.$ )$=-1.84 \mathrm{~V}$ vs SCE, , and excitation energy $\mathrm{E}_{0,0}=2.15 \mathrm{eV}$ at $\lambda_{\mathrm{ex}}=557 \mathrm{~nm}$ and $\mathrm{E}_{0,0}=2.46 \mathrm{eV}$ at $\lambda_{\mathrm{ex}}=440$ $\mathrm{nm}$, the excited state redox potentials of this helicene radical are estimated to be $E^{*}{ }_{1 / 2}^{o x}\left(\mathrm{C}^{+} / \mathrm{C}^{* *}\right)=-3.03 \mathrm{~V}$ vs $\operatorname{SCE}\left(\lambda_{\mathrm{ex}}=557 \mathrm{~nm}\right), E^{*_{1 / 2}{ }^{o x}}\left(\mathrm{C}^{+} / \mathrm{C}^{* *}\right)=-3.31 \mathrm{~V}$ vs SCE $\left(\lambda_{\mathrm{ex}}=440 \mathrm{~nm}\right)$, and $E^{*}{ }_{1 / 2}^{\text {red }}\left(\mathrm{C}^{* *} / \mathrm{C}^{-}\right)=+0.45 \mathrm{~V}$ vs SCE (see supplementary information). As a result, ${ }^{n} \operatorname{Pr}-\mathrm{DMQA}{ }^{*}$ can be described as a mild photooxidant and one of the most potent photoreductant.

Considering recent reports suggesting that in-situ generated close-shell singlets can be involved during photochemical transformations, ${ }^{18}$ we turned our focus on ${ }^{n}$ Pr-DMQA-H. Following Lacour et. al. synthetic protocol, ${ }^{26}$ we have synthesized and studied the electro- and photophysical properties of this neutral close shell singlet (see supporting information). The absorption spectroscopy reveals a photo inactive species that possesses an absorption at $316 \mathrm{~nm}$ and no emission. The cyclic voltammogram of ${ }^{n} \mathrm{Pr}-\mathrm{DMQA}-\mathrm{H}$ (Figure 2c, iii) traces) reveals an irreversible oxidation event at $+0.67 \mathrm{~V}$ vs SCE, followed by a reversible oxidation at $+1.27 \mathrm{~V}$ vs SCE which was assigned to the ${ }^{n} \mathrm{Pr}-\mathrm{DMQA}^{++\bullet} /{ }^{n} \mathrm{Pr}-\mathrm{DMQA}^{+}$redox couple. Importantly, no event is observed at negative potential during the first cycle (solid trace), however the reversible event associated to ${ }^{n} \mathrm{Pr}-\mathrm{DMQA}^{+} /{ }^{n} \mathrm{Pr}-\mathrm{DMQA}^{*}$ appears after the second cycle (doted trace) suggesting that ${ }^{n} \mathrm{Pr}-$ $\mathrm{DMQA}^{+}$is electrochemically generated from the oxidation of ${ }^{n} \mathrm{Pr}-\mathrm{DMQA}-\mathrm{H}$. Consistent with these electrochemical data and the previous observation by Lacour, UV-Vis spectroscopy monitoring of the colorless ${ }^{n} \mathrm{Pr}-\mathrm{DMQA}-\mathrm{H}$ revealed the slow formation of the green ${ }^{n} \mathrm{Pr}-\mathrm{DMQA}^{+}$upon exposure to air in acetonitrile (see Figure 2d, left). ${ }^{27}$ Interestingly, ${ }^{n} \mathrm{Pr}-\mathrm{DMQA}-\mathrm{H}$ was stable in acetonitrile in absence of oxygen and in the dark, but undergoes photoinduced homolysis to form ${ }^{n} \mathrm{Pr}-\mathrm{DMQA}{ }^{*}$ when irradiated with a $440 \mathrm{~nm}$ LED. This conversion was also monitored by UV-Vis spectroscopy (Figure S12). These results support that even if formed during photocatalysis (vide-infra), the closed shell single ${ }^{n} \mathrm{Pr}-\mathrm{DMQA}-\mathrm{H}$ is expected to convert back to ${ }^{n} \mathrm{Pr}-\mathrm{DMQA}^{*}$ via photolysis and/or to ${ }^{n} \mathrm{Pr}-\mathrm{DMQA}^{+}$under oxidative conditions, undermining its involvement as a possible photoinduced electron transfer agent. 

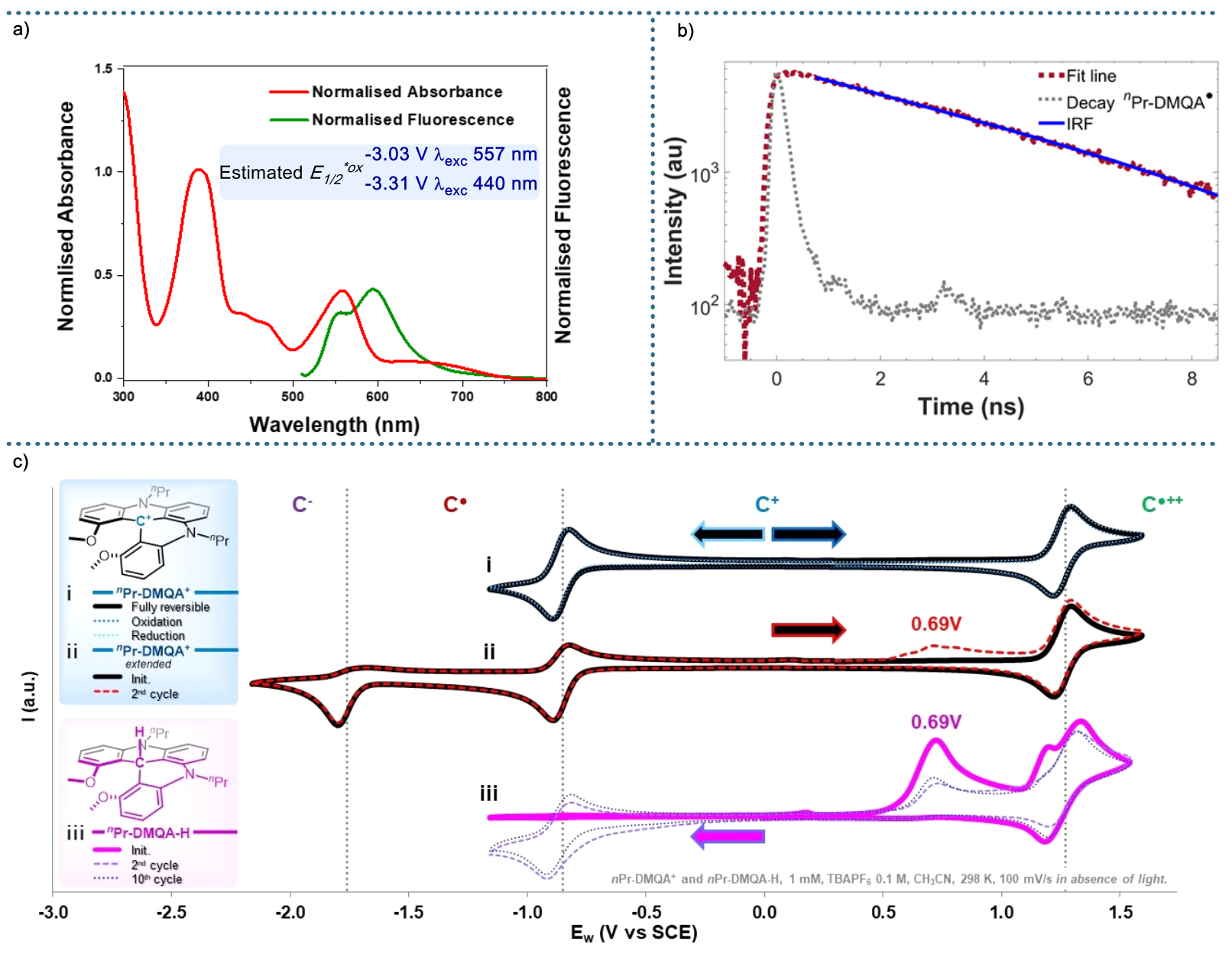

Figure 2: Characterization of isolated ${ }^{n}$ Pr-DMQA radical. a, Absorbance, emission and estimated excited oxidation potential of ${ }^{n} \operatorname{Pr}-\mathrm{DMQA}$. b. The fluorescence lifetime decay profiles of ${ }^{n} \mathbf{P r D M Q A}{ }^{\text {' }}$ $\left(1 \times 10^{-5} \mathrm{M}\right)$ in $\mathrm{MeCN}, \tau=4.4 \mathrm{~ns}\left(\lambda_{\mathrm{ex}}=420 \mathrm{~nm}\right.$ and monitoring emission at $\left.\lambda_{\mathrm{em}}=593 \mathrm{~nm}\right) ; \mathbf{c}$, Redox properties of ${ }^{n}$ Pr-DMQA ${ }^{*}{ }^{n}$ Pr-DMQA ${ }^{+}$and ${ }^{n}$ Pr-DMQA-H.

Photochemical activity of "PrDMQA' radical. The photoactivity of ${ }^{n} \mathrm{Pr}-\mathrm{DMQA}^{*}$ as a potent single electron transfer agent was first investigated using UV-visible (UV-Vis) spectroscopy by monitoring, the irradiation of a solution containing ${ }^{n} \mathrm{Pr}-\mathrm{DMQA}{ }^{*}$ and excess of 4-bromo anisole $\left(E_{1 / 2}{ }^{\text {red }}=-2.90 \mathrm{~V}\right.$ vs SCE$)$ with a $440 \mathrm{~nm}$ and a $640 \mathrm{~nm}$ LED (Figure 3a, and Figure S15 - S17). Under $640 \mathrm{~nm}$ irradiation or in absence of light no change to the UV-Vis spectra were observed (Figure S15 and S17). However, under 440 $\mathrm{nm}$ irradiation we observed the disappearance of the radical ${ }^{n} \mathrm{Pr}$-DMQA ${ }^{*}$ absorption band and the appearance of the cation ${ }^{n} \mathrm{Pr}-\mathrm{DMQA}^{+}$absorption bands (Figure 3a). These observations suggest that the excited state ${ }^{n} \mathrm{Pr}-\mathrm{DMQA} * *$ can undergo an oxidative quenching process via SET with aryl halide to generate an aryl radical anion and ${ }^{n} \mathrm{Pr}-\mathrm{DMQA}^{+}$. The photoredox properties of ${ }^{n} \mathrm{Pr}-\mathrm{DMQA}{ }^{*}$ discussed above also suggest that in presence of a suitable donor $\left(E_{1 / 2}>+0.45 \mathrm{~V}\right.$ vs SCE), reductive quenching of ${ }^{n} \operatorname{Pr}-\mathrm{DMQA} *$ can be observed resulting in the formation of the highly reactive ${ }^{n} \mathrm{Pr}-\mathrm{DMQA}^{-}$which will then rapidly convert to the stable singlet closed shell ${ }^{n} \mathrm{Pr}-\mathrm{DMQA}-\mathrm{H}$ (vide-supra). UV-Vis spectroscopy monitoring of a solution of ${ }^{n} \mathrm{Pr}-\mathrm{DMQA}{ }^{\prime}$ and a large excess of pyrrolidine under $440 \mathrm{~nm}$ LED irradiation revealed the rapid and 
quantitative formation of ${ }^{n} \mathrm{Pr}-\mathrm{DMQA}-\mathrm{H}$ (Figure 3b). A large excess of amine was required to drive the reaction toward the formation of ${ }^{n} \mathrm{Pr}-\mathrm{DMQA}-\mathrm{H}$ and overcome the reverse photolysis of ${ }^{n} \mathrm{Pr}-\mathrm{DMQA}-\mathrm{H}$ back to ${ }^{n} \operatorname{Pr}-\mathrm{DMQA}$.

To further probe the viability of a photoexcited direct SET between ${ }^{n}$ Pr-DMQA and aryl halides we performed a stoichiometric photo-Arbuzov reaction using different light sources (440 nm and $640 \mathrm{~nm}$ ), different DMQA species ( $\left.{ }^{n} \mathrm{Pr}-\mathrm{DMQA}{ }^{*}{ }^{n} \mathrm{Pr}-\mathrm{DMQA}^{+},{ }^{n} \mathrm{Pr}-\mathrm{DMQA}-\mathrm{H}\right)$, and different aryl bromide substrates with a range of reduction potentials (4-bromo benzonitrile $2 \mathrm{a}, E_{1 / 2}{ }^{\text {red }}=-1.94 \mathrm{~V}$ vs SCE; and 4-bromo anisole $\mathbf{2 b}, E_{1 / 2}{ }^{\text {red }}=-2.90 \mathrm{~V}$ vs SCE) (Figure 3c, and supporting information). Equimolar amounts of aryl bromide and DMQA species were irradiated for $16 \mathrm{~h}$ with visible light in presence of 3.0 equivalent of the aryl radical trapping agent, triethyl phosphite $\mathrm{P}(\mathrm{OEt})_{3}$. Using $\mathrm{DMQA}^{+}$, under either $440 \mathrm{~nm}$ or $640 \mathrm{~nm}$ irradiation, did not produced any aryl activated product consistent with the mild photoreducing potential of this singlet cation species (See Figure 3c, entry 1 - 2). On the other hand, when the doublet neutral radical ${ }^{n}$ Pr-DMQA ${ }^{*}$ was irradiated under $440 \mathrm{~nm}$ both aryl halides were activated, with a higher yield for the less electron rich bromo benzonitrile (3a, $<90 \%$ yield) and $\mathbf{3 b}, 50 \%$ yield, Figure 3c, entry 3). Furthermore, the red color of the reaction mixture, characteristic of the helicene radical, turned to the blue/green color of the helicenium ion supporting the previously observed reversibility between radical and cationic form of the DMQA system. Importantly, no product formation for the electron rich 4-bromo anisole was observed when red light irradiation $(640 \mathrm{~nm}$ ) was used (Figure 3c, entry 4), consistent with the weak absorption of ${ }^{n}$ Pr-DMQA ${ }^{*}$ at wavelength higher than $600 \mathrm{~nm}$ (Figure 1c). However, full conversion was detected under red light with the more easily reducible 4-bromo benzonitrile suggesting that an alternative pathway to PET maybe involved with this easily activated substrate (Figure 3c, entry 4). Finally, we noted a similar outcome when using ${ }^{n} \mathrm{Pr}-\mathrm{DMQA}-\mathrm{H}$ (Figure 3c, entry 5 - 6), which supports the formation of ${ }^{n} \mathrm{Pr}-\mathrm{DMQA}{ }^{*}$ under light. These results substantiated our hypothesis that the doublet neutral helicene radical ${ }^{n} \mathrm{Pr}-\mathrm{DMQA}{ }^{*}$ can undergo rapid PET with substrates such as electron rich aryl bromide under $440 \mathrm{~nm}$ light.

To further support these observations and the ability for ${ }^{n} \mathrm{Pr}-\mathrm{DMQA}^{*}$ to undergo single electron transfer with aryl halides, we performed transient absorption measurements using a home-built apparatus with broadband detection (see supporting information). Transient absorption data was collected for the neutral radical in acetonitrile and in an acetonitrile/4-bromo anisole (3.0 equiv.) solution. Figure 3d (i) presents the transient absorption data for the ${ }^{n} \mathrm{Pr}$-DMQA' neutral radical in acetonitrile. The region corresponding to the maximum of the negative ground state bleach signal has been omitted due to pump scatter. Stimulated emission signal expected appear at the maximum of the fluorescence emission is not evident as it is overlapped with the strong excited state absorption signal. Two excited state absorptions that appear as positive signals with maxima at $523 \mathrm{~nm}$ and $588 \mathrm{~nm}$ are present in the data on either side of the ground state bleach. Both excited state absorption contributions fully decay by $48 \mathrm{ps}$ as shown in Figure 3d (i). At longer delay times, the only remaining signal arises from the recovery of the ground state bleach, which corresponds to the $4.6 \pm 0.2 \mathrm{~ns}$ excited state lifetime measured by TCSPC. Figure 3d (ii) presents the transient absorption for the ${ }^{n} \mathrm{Pr}-\mathrm{DMQA}^{\cdot}$ neutral radical in acetonitrile in the presence of an aryl halide. In comparison to the ${ }^{n} \mathrm{Pr}-\mathrm{DMQA}{ }^{*}$ alone in acetonitrile, the addition of the aryl halide produces significant changes in the transient absorption data. Both samples have similar nanosecond ground state recoveries (negative signal centered at $558 \mathrm{~nm}$ ) consistent with the measured fluorescent lifetime, with different dynamics evident for the positive going contributions on either side of the ground state bleach. The positive signal features in the neutral radical in acetonitrile data decay within tens of picoseconds. In contrast, the signal for the neutral radical in the presence of an aryl halide has positive features that persist for 
nanoseconds. The maxima of the lower energy positive feature in the data with the aryl halide is peaked at $615 \mathrm{~nm}$ rather than $588 \mathrm{~nm}$ for the acetonitrile-only solution. This indicates the in-situ generation of the cation ${ }^{n} \mathrm{Pr}-\mathrm{DMQA}^{+}$photoproduct whose $\mathrm{S} 0$ to $\mathrm{S} 1$ transition is peaked at $616 \mathrm{~nm}$. The persistence of the cation photoproduct signal is consistent with the previously measured excited state lifetime of $5.7 \mathrm{~ns}$.
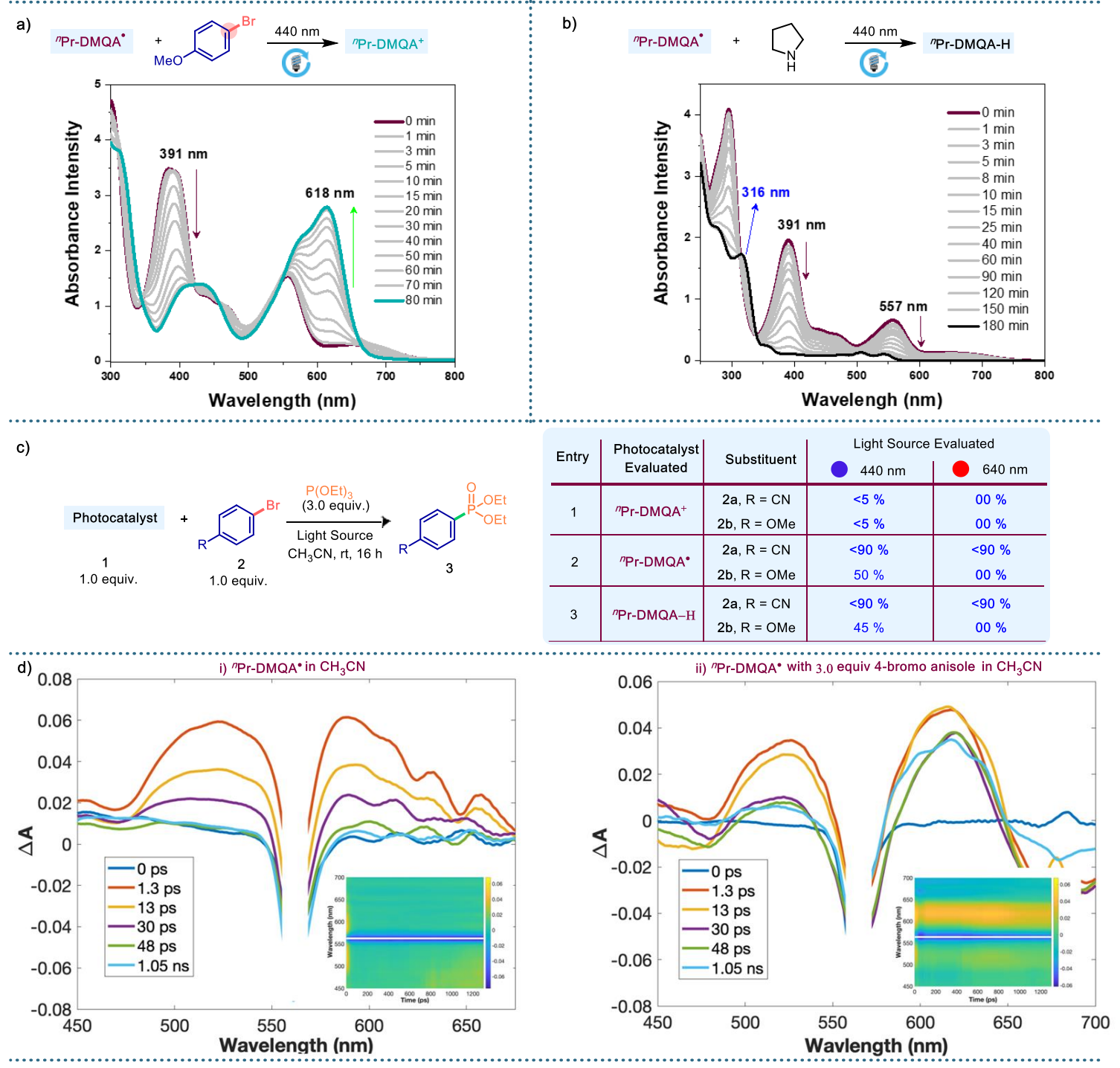

Figure 3: a, UV-visible spectroscopic analysis between ${ }^{n} \mathrm{Pr}-\mathrm{DMQA}^{\bullet}$ and aryl halide at $440 \mathrm{~nm}$ irradiation. b, UV-visible spectroscopic analysis between ${ }^{n} \mathrm{Pr}-\mathrm{DMQA}^{*}$ and amine. c, Photo-Arbuzov reaction to evaluate direct SET pathway and a proof of concept for extreme photoreducing ability of photoexcited isolated " $\mathrm{Pr}$-DMQA". d, Transient absorption data at selected time points for ${ }^{n} \mathrm{Pr}-\mathrm{DMQA}{ }^{*}$ in acetonitrile with an inset of the transient absorption surface. e) Transient absorption data at selected time points for ${ }^{n} \operatorname{Pr}-$ $\mathrm{DMQA}^{*}$ in acetonitrile in the presence of an 4-bromo anisole with an inset of the transient absorption surface.

Photocatalytic activity of ${ }^{n}$ Pr-DMQA radical and mechanism. Inspired by the stoichiometric photoArbuzov experiment and our previous reports on the photoactivity of ${ }^{n} \operatorname{Pr}-\mathrm{DMQA}^{+}$, we questioned if ${ }^{n} \mathrm{Pr}$ DMQA $^{*}$ can be photochemically generated from ${ }^{n} \mathrm{Pr}-\mathrm{DMQA}^{+}$in presence of a light source and an electron 
donor, allowing the use of ${ }^{n} \mathrm{Pr}-\mathrm{DMQA}^{*}$ as potent photoreducing agent for catalytic transformations. Consistent with our previous observation, the successful generation of the helicene radical ${ }^{n} \mathrm{Pr}-\mathrm{DMQA}{ }^{*}$ was detected in an EPR experiment, as well as using UV-Vis spectroscopy, in presence of three different electron donors under both blue and red-light sources (Figure 4a, and Figure S24 - S28). Next, we attempted the catalytic reductive dehalogenation of 4-bromobenzonitrile $\left(\mathrm{E}_{1 / 2}=-1.94 \mathrm{~V} \text { and } \mathrm{BDE}=80 \mathrm{kcal} / \mathrm{mol}\right)^{28}$ and 4-bromoanisole $\left(\mathrm{E}_{1 / 2}=-2.90 \mathrm{~V}\right.$ and $\left.\mathrm{BDE}>85 \mathrm{kcal} / \mathrm{mol}\right)$ in presence of pyrrolidine with ${ }^{n} \mathrm{Pr}-\mathrm{DMQA}^{+}$or ${ }^{n} \mathrm{Pr}-$ DMQA $^{*}$ as a photocatalyst under either blue or red light (Figure $\mathbf{4 b}$, and supporting information). In case of 4-bromo anisole, both PCs induced a dehalogenation reaction under blue light with similar yields. The near identical yield for both PCs supports a mechanism during which ${ }^{n} \mathrm{Pr}-\mathrm{DMQA}^{+}$and ${ }^{n} \mathrm{Pr}-\mathrm{DMQA}{ }^{*}$ are involved in the photocatalytic cycle (Figure 4b). However, no product was detected with either PCs when low energy light was employed, consistent with the fact that ${ }^{n} \mathrm{Pr}-\mathrm{DMQA}{ }^{*}$ has little to no absorption in red light, and that ${ }^{n} \operatorname{Pr}-\mathrm{DMQA}^{+*}$ is not reductive enough to undergo PET with aryl halides. Similarly, with the electron poor bromobenzonitrile, both PCs afforded full conversion under blue light (Figure 4b). However, unlike with anisole, some conversions were detected with both ${ }^{n} \operatorname{Pr}-\mathrm{DMQA}^{+}$and ${ }^{n} \mathrm{Pr}-\mathrm{DMQA}^{*}$ under low energy red light. We recently, reported that photochemically generated ammonium radical can initiate XAT mechanism with electron poor substrate such as 4-bromobenzonitrile but not with 4-bromoanisole. In the present system, pyrrolidine acts as an electron donor and forms pyrrolidinium radical during the photoreduction of ${ }^{n} \mathrm{Pr}-\mathrm{DMQA}^{+}$to ${ }^{n} \mathrm{Pr}-\mathrm{DMQA}^{*}$ or ${ }^{n} \mathrm{Pr}-\mathrm{DMQA}{ }^{\cdot}$ to ${ }^{n} \mathrm{Pr}-\mathrm{DMQA}$. The lower yield observed in red light compared to blue light for bromobenzonitrile supports that single electron transfer between ${ }^{n} \mathrm{Pr}$ DMQA* and aryl halides is the most effective mechanistic pathway. Together, these observations suggest that for electron poor substrate such as bromobenzonitrile both SET and XAT mechanism are accessible pathways in blue light while XAT is the only viable mechanism under red light. On the other hand, for electron rich species such as 4-bromo anisole, SET from ${ }^{n} \mathrm{Pr}$-DMQA** is the only sustainable mechanism. Interestingly, at the end of the catalytic transformations under blue light, the reaction mixtures were a pale almost colorless solution which rapidly turn to the green color of ${ }^{n} \mathrm{Pr}-\mathrm{DMQA}^{+}$when exposed to air. This observation suggests that at high conversion (excess amine and low concentration of aryl halide) ${ }^{n} \operatorname{Pr}-$ DMQA-H generated from ${ }^{n}$ Pr-DMQA** build up in solution and can be considered as an off-cycle catalytic resting state.

Based on these experimental results and previous reports, we proposed a plausible conPET pathway for the photoactivation of electron rich aryl halides using ${ }^{n} \mathrm{Pr}-\mathrm{DMQA}^{+}$as photocatalyst under blue light (Figure 4c). First the photoexcitation of ${ }^{n} \mathrm{Pr}-\mathrm{DMQA}^{+}$results in an excited cationic ${ }^{n} \mathrm{Pr}-\mathrm{DMQA}^{+*}$ under blue light irradiation. A single electron transfer (SET) from the sacrificial electron donor D (pyrrolidine, DIPEA or enamine) generates the neutral helicene radical ${ }^{n} \mathrm{Pr}-\mathrm{DMQA}{ }^{*}$. As the radical species is photoactive in the blue light region the second photoexcitation leads to the excited state helicene radical, ${ }^{n} \mathrm{Pr}-\mathrm{DMQA} *$. Now the electrochemical potential of this excited neutral radical $\left(E_{1 / 2}^{\text {red }}<-3.31 \mathrm{~V}\right.$ vs SCE in $\mathrm{CH}_{3} \mathrm{CN}, \tau=4.6 \pm$ $0.2 \mathrm{~ns}$ ) is strong enough to reduce aryl chlorides and bromides via SET closing the catalytic cycle by regenerating the cationic helicenium ${ }^{n} \mathrm{Pr}-\mathrm{DMQA}^{+}$. Finally, after reduction the aryl halide radical anion fragmentate to the corresponding aryl radical which can abstract a hydrogen to form the dehalogenated product, or be further coupled with suitable substrates (phosphites, boranes, pyrroles or carbonyls). In a non-productive pathway, the excited state helicene radical ${ }^{n} \mathrm{Pr}-\mathrm{DMQA} *$ can also generate ${ }^{n} \mathrm{Pr}-\mathrm{DMQA}^{-}$via SET with pyrrolidine, followed by the generation of ${ }^{n} \mathrm{Pr}-\mathrm{DMQA}-\mathrm{H}$ which can fragmentate back to ${ }^{n} \mathrm{Pr}-$ DMQA: 


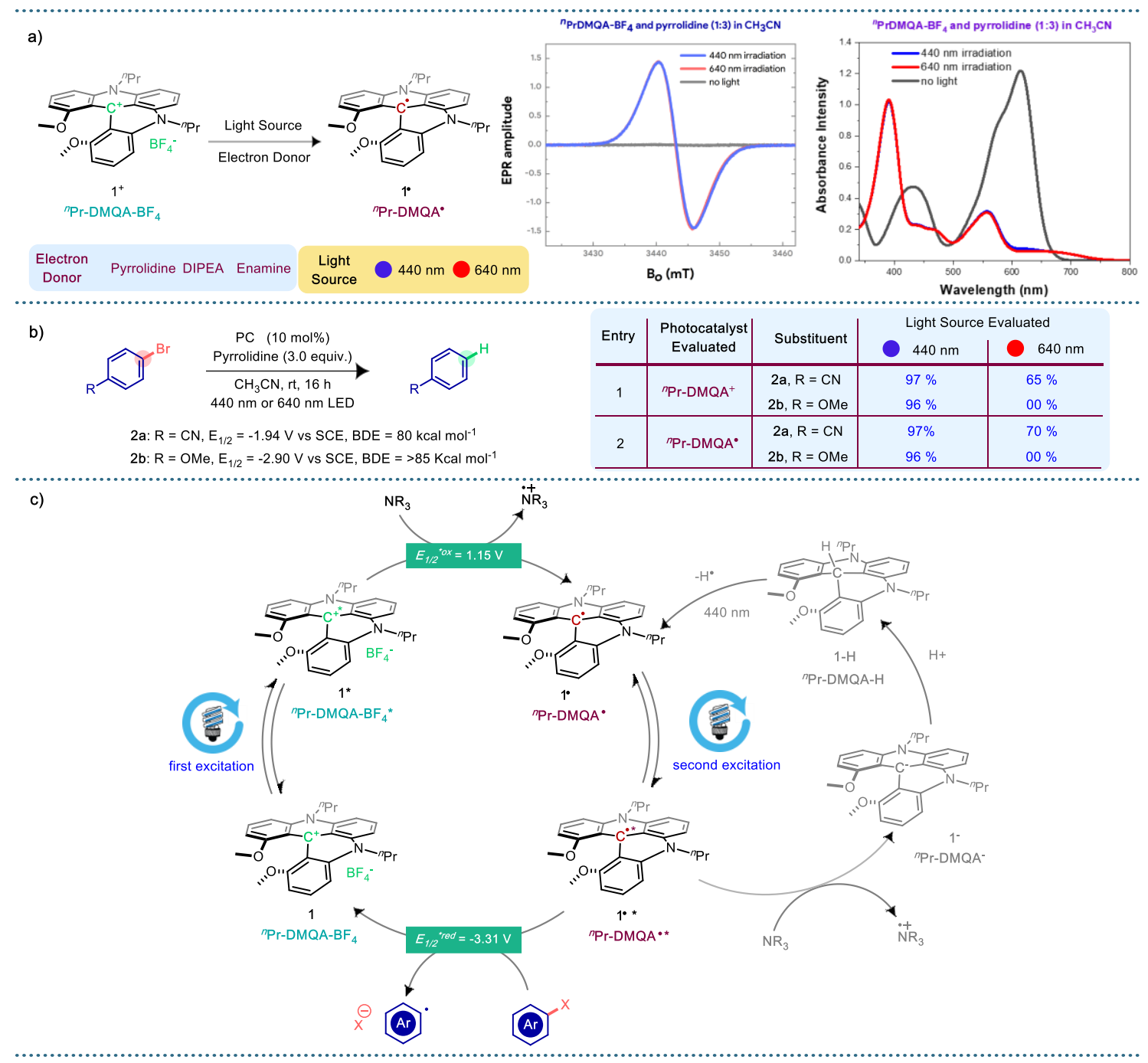

Figure 4: a, Photochemical generation of ${ }^{n} \mathrm{Pr}-\mathrm{DMQA}{ }^{\cdot}$ and detection by EPR spectroscopy and UV-visible spectroscopy. b, Catalytic reductive dehalogenation reaction of aryl bromides. c, Prospective photocatalytic mechanism via two-photon excitation process to generate aryl radical from aryl halide.

Photocatalytic dehalogenation of aryl halides. With the photo-excited behavior of ${ }^{n} \mathrm{Pr}-\mathrm{DMQA}{ }^{\bullet}$ and a probable mechanism for consecutive photoelectron transfer elucidated, we sought to use this neutral helicene radical as a photoreducing catalyst for the functionalization of aryl halides. At first, reductive dehalogenation of aryl halides was performed as the benchmark reaction to evaluate the extent of the extremely potent reducing behavior of the helicene radical. Dehalogenation of 4-bromo anisole $\left(E_{1 / 2}{ }^{\text {red }}=-\right.$ $2.9 \mathrm{~V}$ vs SCE) was optimized using ${ }^{n} \mathrm{Pr}-\mathrm{DMQA}-\mathrm{BF}_{4}$ as the photocatalyst under a $440 \mathrm{~nm}$ light source. Pyrrolidine was identified as an efficient sacrificial electron donor for the generation of ${ }^{n} \mathrm{Pr}-\mathrm{DMQA}{ }^{\bullet}$ from ${ }^{n}$ Pr-DMQA ${ }^{+}$, in situ. After optimization (see Table S1), we observed that 5.0 mol\% ${ }^{n}$ Pr-DMQA-BF 4 as the photocatalyst in presence of $440 \mathrm{~nm}$ blue light and 3.0 equiv. of pyrrolidine furnished the desired hydrodebrominated product (anisole) in 94\% yield within $16 \mathrm{~h}$.

Following the identification of optimal reaction conditions, the competency of this strong radical photoreductant has been demonstrated by the reduction of a wide range of electronically diverse aryl 
chlorides and bromides (Table 1). Successful dehalogenation of a variety of electron rich and electron poor aryl chlorides with reduction potential of $-2.9 \mathrm{~V}$ vs SCE and lower have been demonstrated in good to excellent yields (4a-4f, 81-99\% yield). We then focused on diverse electron rich aryl bromides (4g-4l, 90$98 \%$ yield) along with a myriad of functional group containing substrates (4m-4s, $71-99 \%$ yield) for excellent hydrodebromination reaction. Polyaromatic substrates and heteroaromatic bromides were also found to be efficient substrates for reductive dehalogenation (4t-4x, 80-96 \% yield). Furthermore, the bisreduction of polyhalogenated arenes gave the corresponding bis-dehalogenated products in moderate yield (4y and $\mathbf{4 z}, 73 \%$ and $78 \%$ yield, respectively). In general, aryl halides bearing nitrile (4c, 4o), ester (4d, $\mathbf{4 n})$, trifluoromethyl $(\mathbf{4 e}, \mathbf{4 s})$, ketone $(\mathbf{4 m})$, free acid $(\mathbf{4 p})$, free hydroxy $(\mathbf{4 q})$ and free amine (4r) groups were well tolerated and found to be excellent substrate for this neutral helicene radical catalyzed photoredox dehalogenation method.

\section{Table 1: Substrate scope for the photoredox reductive dehalogenation of aryl halides enabled by neutral helicene radical.}
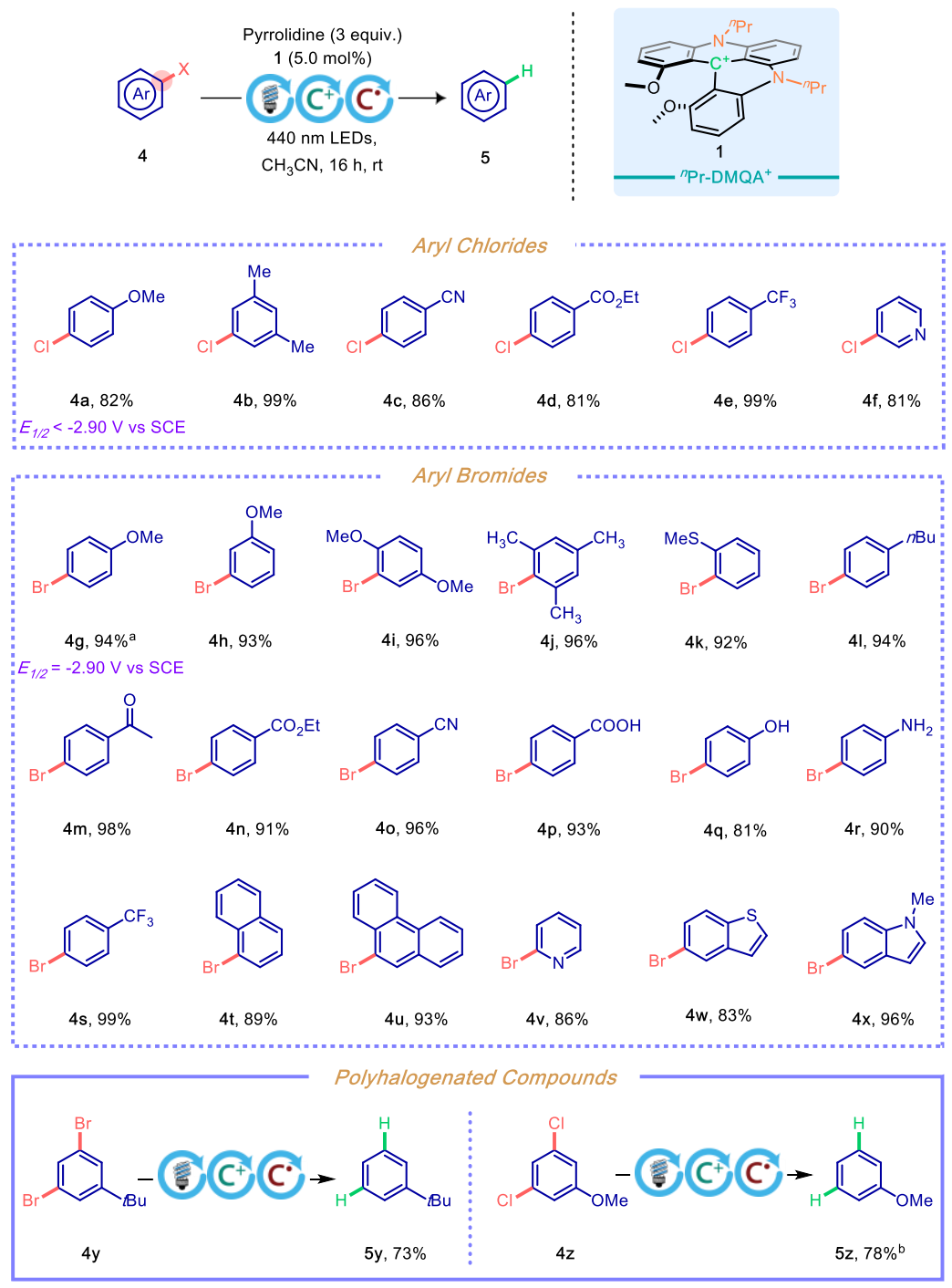

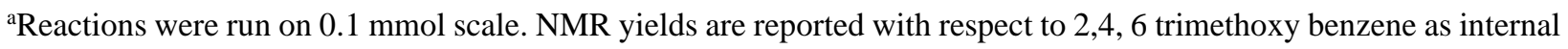
standard. ${ }^{\mathrm{b}} 10 \mathrm{~mol} \%{ }^{n} \mathrm{Pr}-\mathrm{DMQA}-\mathrm{BF}_{4}$ and $0.5 \mathrm{M}$ reaction concentration was used. $E_{1 / 2}$, half-peak potential; LEDs, light-emitting diodes. See ESI for details. 
Photocatalytic functionalization of aryl halides. After successful examination of hydrodehalogenation reaction, we decided to extend this radical photocatalysis to other arene-functionalization processes (Table 2). Aryl phosphonates are important structural motifs found in many pharmaceutically active molecules ${ }^{29}$ and easily accessed by photo-Arbuzov reaction using triethyl phosphite, $\mathrm{P}(\mathrm{OEt})_{3}{ }^{30}$ Addition of 3.0 equiv of $\mathrm{P}(\mathrm{OEt})_{3}$ to the optimal reaction condition of hydrodehalogenation reaction furnished aryl phosphonates in high isolated yields (Table 2 and S2). Using ConPET enable by ${ }^{n} \operatorname{Pr}-\mathrm{DMQA}{ }^{\bullet}$ allow us to expand scope of reactions towards less reactive aryl bromides or aryl chlorides bearing very negative reduction potentials. Electron rich aryl halides with substituents in ortho, meta and para position demonstrated excellent reaction yields (7a-7c, 81-91\% yield). Aryl bromides and chlorides with electron withdrawing groups also showed good conversion to the desired product (7d-7f, 76-89\% yield). In addition to that, polyaromatic substrate (7g, 90\% yield) and heteroaromatic substrates furnished the corresponding aryl phosphonate in excellent yields (7h-7j, 84-92 \% yield). Following the photo-Arbuzov reaction, borylation reaction for synthesis of aryl borate which is considered as important coupling partner in late-stage derivatization, ${ }^{31}$ was examined with this established ConPET using ${ }^{n} \mathrm{Pr}-\mathrm{DMQA}{ }^{\bullet}$. The addition of dipinacol diborane to optimized reductive dehalogenation condition ended up with the formation of aryl borate in good yields (7k-7l, 79-86 \% yield). Furthermore, we explored the photoredox generation of aryl radicals from aryl halides for $\mathrm{C}-\mathrm{C}$ bondforming reactions with arene such as $N$-methyl pyrrole. The desired arylated products were isolated in good yields in presence of 3.0 equiv. of $N$-methyl pyrrole (7m-7n, 88-90 \% yield). During these transformations, dehalogenation was detected as side reaction. The use of DIPEA (Di-isopropylethylene diamine) as electron donor instead of pyrrolidine was found to give more selective result (see supporting information).

\section{Table 2: Scope for the reductive functionalization of aryl halides under photoredox condition} catalyzed by neutral helicene radical.

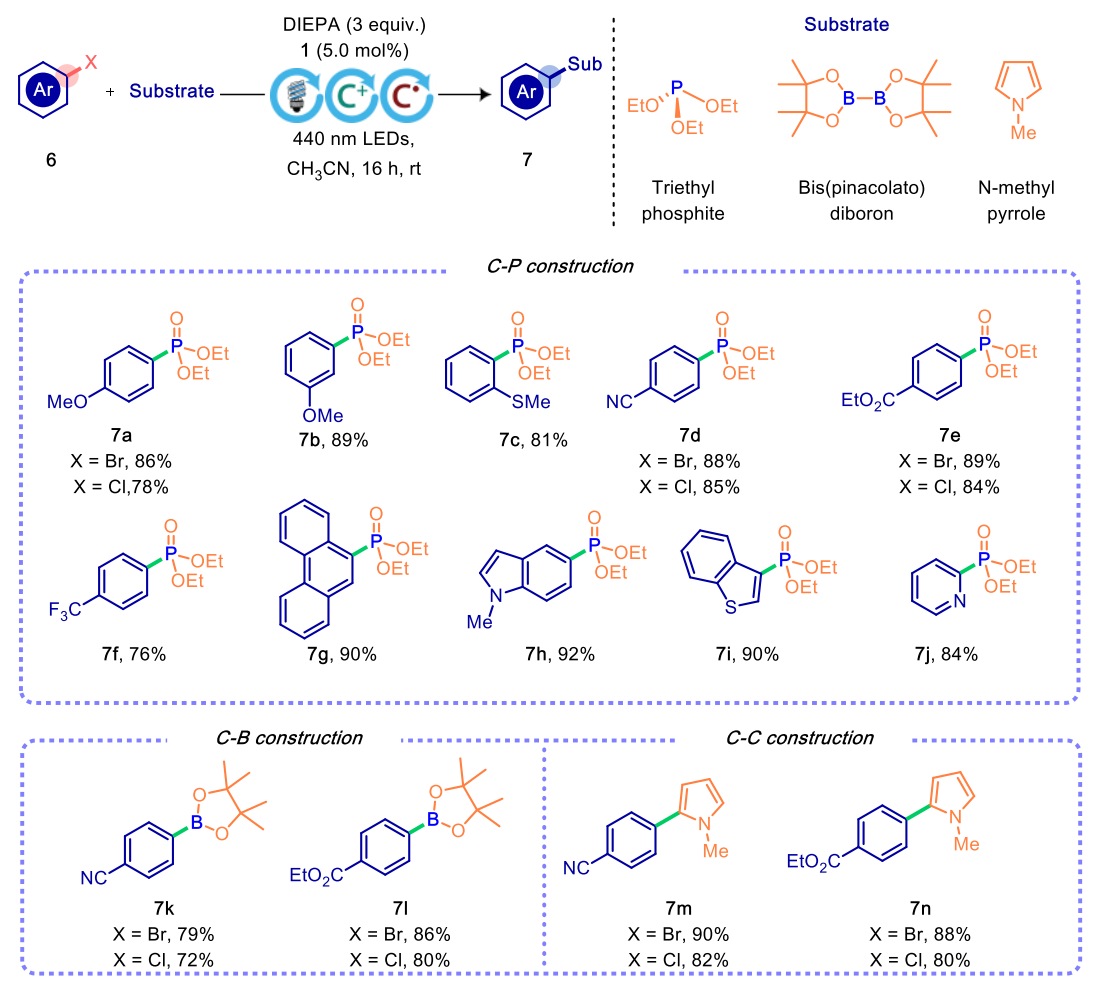

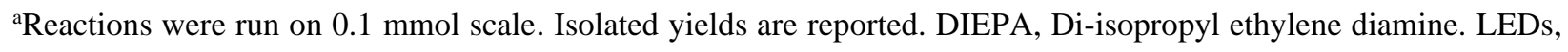
light-emitting diodes. See Supplementary Information for details. 
Photocatalytic $\alpha$-arylation of cyclic ketones. The $\alpha$-arylated cyclic ketone scaffolds are medicinally significant as well as critical building blocks for numerous pharmaceutical agents and bioactive natural products. $^{32}$ Unsurprisingly, transition-metal catalyzed $\alpha$-arylation of carbonyls are well established reactions in classic organic chemistry. Typically, expensive transition metal catalysts and ligands, harsh reaction condition or multistep protocols are employed in the synthesis of medicinally relevant $\alpha$-arylated cyclic ketones. ${ }^{33}$ Nonetheless, considering the medicinal impact of such metal-mediated methods for the synthesis of pharmaceutical drug molecules, a completely organic catalyst based direct $\alpha$-arylation reaction is in high demand. ${ }^{34}$ Recently, our group reported photoredox $\alpha$-arylation of carbonyl compounds using an electron rich acridinium as photocatalyst. However, scope of aryl halide was limited mainly to aryl iodides with moderate to good yields due to the lower excited state potential of our acridinium photocatalyst. ${ }^{35}$ Using the present DMQA system as conPET photocatalyst for $\alpha$-arylation of carbonyls would allow to expand the reaction scope to electron rich aryl bromides. In our contemporary report, ${ }^{35}$ we demonstrated that in-situ enamine formation via condensation reaction between the carbonyl and the amine moieties was required. We further demonstrated that the cyclic amine, pyrrolidine, provided the highest yield due to the rapid enamine formation, and that both the pyrrolidine and its enamine analog acted as sacrificial electron donor. The EPR analysis of ${ }^{n} \mathrm{Pr}-\mathrm{DMQA}-\mathrm{BF}_{4}$ in presence of enamine confirms the formation of ${ }^{n} \mathrm{Pr}-\mathrm{DMQA}{ }^{*}$ in a photoexcited state. Furthermore, using a readily available enamine (1-pyrrolidino-1-cyclohexene) as sacrificial electron donor instead of pyrrolidine, under optimized condition of reductive dehalogenation, resulted in the formation $\alpha$-arylated of cyclohexanone, $85 \%$ yield. (See supporting information). Literature studies showed that enamine radical cations mainly exhibit the $\mathrm{C}$-center free radical property due its high spin population, ${ }^{36}$ which can lead to radical recombination pathway for generation of alpha-substituted product. Hence, to develop the helicene radical catalyzed $\alpha$-arylation of carbonyls we employed cyclohexanone and pyrrolidine with aryl bromides. Optimizations under catalytic condition showed that 4bromoethyl benzoate (1.0 equiv.) in presence of $5 \mathrm{~mol} \%$ of ${ }^{n} \mathrm{Pr}-\mathrm{DMQA}-\mathrm{BF}_{4}$ and combination of cyclohexanone with pyrrolidine (3.0 equiv. each) furnished the desired alpha-arylated product in $86 \%$ yield (See Table S4).

With these optimal conditions for the alpha-arylation of cyclic ketones in hand, we examined the scope with respect to the aryl bromide component. As shown in Table 3, para-substituted bromoarenes containing functional groups like ester, carbonyl and free acid generated the corresponding alpha-arylated product in very good yields (8a-8d, 84-88\% yield). Medicinally significant functional groups like nitrile and trifluoromethyl substituted arylbromides were also evaluated. Gratifyingly, substitution in para or meta position did not affect the product yield neither in nitrile (8e and 8f, 86 and $82 \%$ yield) nor in trifluoromethyl containing substrates $(\mathbf{8 g}$ and $\mathbf{8 h}, 75$ and $76 \%$ yield). Fluorinated bromobenzene and unsubstituted bromobenzene were also well accommodated, furnishing alpha-arylated adducts in good yield (8i and $\mathbf{8 j}, 81$ and $80 \%$ yield). In addition, polyaromatic and heteroaromatic bromoarene like 9bromophenanthrene and bromoindole were also found to be excellent substrate for this transformation (8k and 81, 74 and $76 \%$ yield). Finally, as a demonstration that this method can be extended to the installation of multiple chiral centers containing arenes, alpha-arylation can be accomplished using this new protocol to provide the corresponding alpha-arylated cyclic ketone in excellent efficiencies ( $\mathbf{8 m}$ and $\mathbf{8 n}, 82$ and 80\% yield). Similar to aryl bromides, different cyclic ketones were also evaluated with respect to the optimal conditions. As shown in Table 3, a series of differentially substituted cyclohexanone-derived substrates were readily coupled with an aryl radical. It is of note that incorporation of both alkyl and aryl substituents at positions 4 of the cyclohexanone ring is well-tolerated (8o-8s, $78-84 \%$ yield). As expected, the presence of single substituent at the 4-position in the cyclohexanone ring induced higher levels of diastereoselectivity 
in product. Disubstituted cyclohexanones at the 4-position of the ring also successfully transformed to the corresponding alpha-arylated derivatives in good yield (8t and 8u, 86 and $82 \%$ yield). Spirocyclic cyclohexanone derivative and heteroatom containing cyclic ketone were also well tolerated in optimal reaction condition $(\mathbf{8 v}$ and $\mathbf{8 w}, 80$ and $78 \%$ yield). Interestingly, cyclopentanone was also found to be an efficient ketone substrate for this transformation with an excellent yield $(\mathbf{8 x}, 85 \%$ yield).

\section{Table 3: Helicene radical catalyzed photoredox a-arylation of cyclic ketones using aryl bromides.}
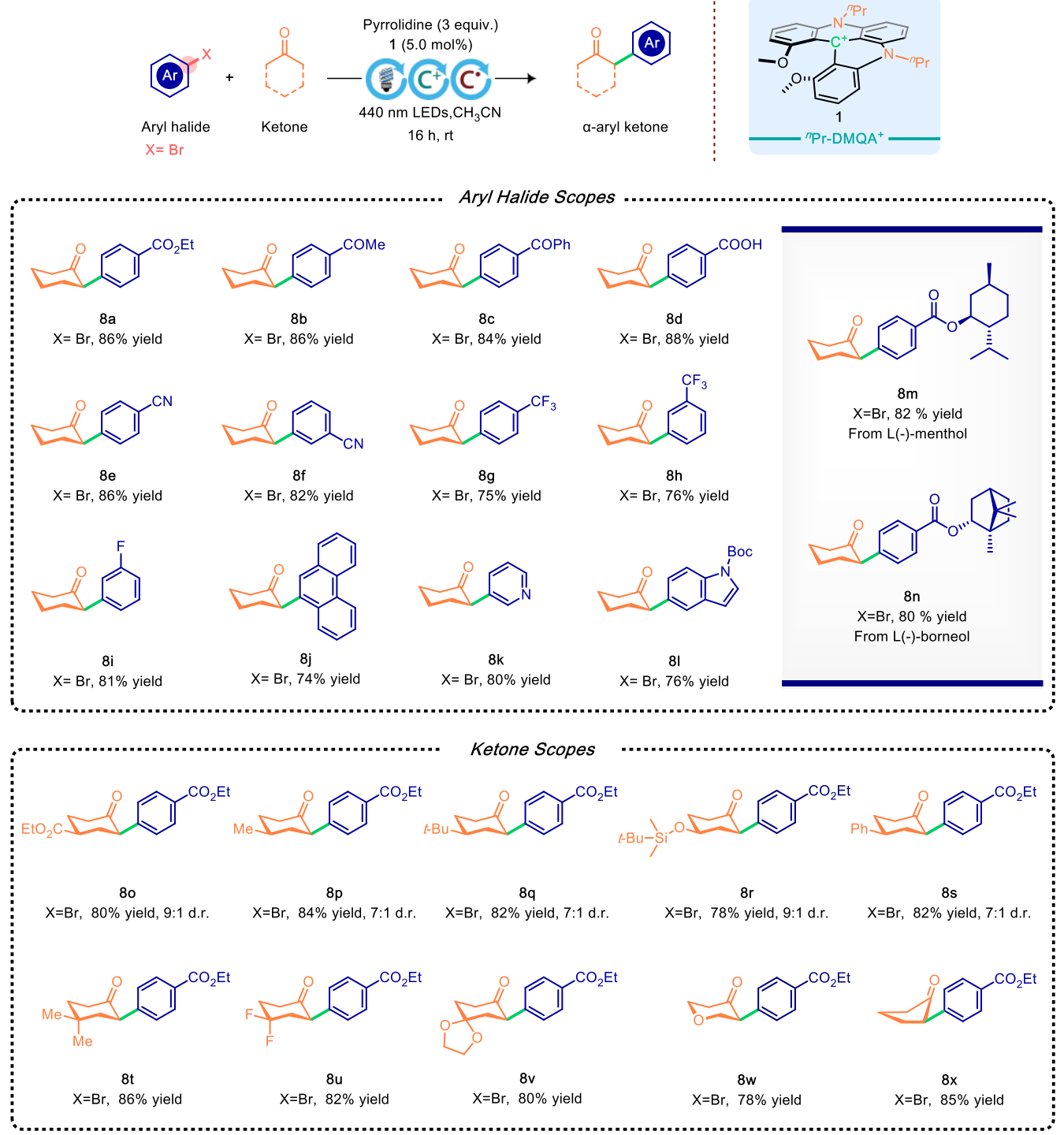

aReactions were run on $0.2 \mathrm{mmol}$ scale. Isolated yields are reported. See Supplementary Information for details.

\section{CONCLUSIONS}

While several reports have supported the involvement of openshell doublet radicals as potent photoreducing species, the isolation of a stable photoactive radical that can allow an extensive mechanistic study of photoinduced electron transfer during an organic transformation has remained elusive. Herein, we have reported that $N, N^{\prime}$-di- $n$-propyl-1,13-dimethoxyquinacridine ( $\left.{ }^{n} \operatorname{Pr}-\mathrm{DMQA}^{*}\right)$, a stable and isolable open shell doublet radical, is a photoactive neutral helicene radical. The facile synthesis and isolation of this helicene 
radical asl allowed us to investigate its photophysical properties, photochemical reactivities and photocatalytic abilities. First, we reported that ${ }^{n} \mathrm{Pr}$-DMQA ${ }^{*}$ possess strong absorption of light in the visible region (391nm, $440 \mathrm{~nm}, 467 \mathrm{~nm}$, and $557 \mathrm{~nm}$ ), exhibits emission maxima at $593 \mathrm{~nm}$, and an excited state lifetime of $4.6 \pm 0.2 \mathrm{~ns}$. The photophysical and electrochemical properties of ${ }^{n} \mathrm{Pr}-\mathrm{DMQA}{ }^{*}$ suggest that this radical possesses an estimated excited state oxidation potential of $-3.31 \mathrm{~V}$ vs $\operatorname{SCE}\left(E_{1 / 2}\left(\mathrm{C}^{+} / \mathrm{C}^{*} *\right)\right)$ and excited state reduction potential of $+0.45 \mathrm{~V}$ vs $\operatorname{SCE}\left(E_{1 / 2}\left(\mathrm{C}^{* *} / \mathrm{C}^{-}\right)\right)$. Monitoring by UV-Visible spectroscopy the irradiation of ${ }^{n} \mathrm{Pr}-\mathrm{DMQA}{ }^{*}$ in acetonitrile at $440 \mathrm{~nm}$ in presence of electron acceptor (aryl halide) or electron donor (amine) revealed that in both cases photoinduced electron transfer occurred leading to the formation of the cationic ${ }^{n} \mathrm{Pr}-\mathrm{DMQA}^{+}$and the anionic ${ }^{n} \mathrm{Pr}-\mathrm{DMQA}^{-}$respectively. The anionic ${ }^{n} \mathrm{Pr}-\mathrm{DMQA}^{-}$was found to rapidly convert to the photo-inactive closed shell singlet ${ }^{n} \mathrm{Pr}-\mathrm{DMQA}-\mathrm{H}$. These observations were further supported by transient absorption spectroscopy which showed that ${ }^{n} \operatorname{Pr}-\mathrm{DMQA} * \cdot$ undergoes efficient single electron transfer with an aryl halides electron acceptor -. We then probed the photoreducing ability of ${ }^{n} \operatorname{Pr}-$ DMQA' using stoichiometric photo-Arbuzov reaction with an electron poor (4-bromo benzonitrile) and an electron rich (4-bromo anisole) aryl bromide, under both 440 and $640 \mathrm{~nm}$. The results obtained, coupled to the control experiments using ${ }^{n} \mathrm{Pr}-\mathrm{DMQA}^{+}$and ${ }^{n} \mathrm{Pr}-\mathrm{DMQA}-\mathrm{H}$, substantiate that the helicene radical is a potent photoreducing agent under $440 \mathrm{~nm}$ irradiation. Similar results were obtained for the catalytic dehydrogenation of the same aryl bromides. Experimental and spectroscopic studies suggest that the neutral helicene radical act as a strongly reducing species and is photochemically regenerated from the cationic helicenium analog, implying that a consecutive photoexcitation mechanism is the most viable mechanistic pathway. The strongly photoreducing nature of a neutral helicene radical ${ }^{n}$ Pr-DMQA ${ }^{*}$ was further used for the well-studied photo-dehalogenation, photo-Arbuzov, photo-borylation and $\mathrm{C}-\mathrm{C}$ bond formation reactions. Additionally, this catalytic system was used in synthesis alpha-arylated cyclic ketones which is considered as an important building block for medicinal chemistry. In summary, we believe that the conPET process enabled by this neutral helicene radical, together with its operational simplicity and sustainability, will help to understand radical photoredox catalysis as well as considered as alternative way for streamline the synthesis of complex functionality in both academia and industry.

\section{ASSOCIATED CONTENT:}

Supporting Information: The Supporting Information is available free of charge at https://pubs.acs.org/doi/XXXXXXXXXXX.

Detailed experimental procedures, analytical data, and computational data (PDF).

\section{AUTHOR INFORMATION}

\section{Corresponding Author}

Thomas L. Gianetti - Department of Chemistry and Biochemistry, University of Arizona, Tucson, Arizona 85721, United States; orcid.org/0000-0002-3892-3893; Email: tgianetti@arizona.edu

\section{Authors}

Aslam C Shaikh - Department of Chemistry and Biochemistry, University of Arizona, Tucson, Arizona 85721, United States. orcid.org/0000-0001-8818-2344.

Md Mubarak Hossain - Department of Chemistry and Biochemistry, University of Arizona, Tucson, Arizona 85721, United States. orcid.org/0000-0002-9828-9492.

Ramandeep Kaur - Department of Chemistry and Biochemistry, University of Arizona, Tucson, Arizona 85721, United States. orcid.org/0000-0001-9735-5104. 
Jules Moutet - Department of Chemistry and Biochemistry, University of Arizona, Tucson, Arizona 85721, United States. orcid.org/ 0000-0002-4390-4769.

Anshu Kumar - Department of Chemistry and Department of Physics, University of Arizona, Tucson, AZ 85721, United States. orcid.org/0000-0001-5949-6248.

Benjamin Thompson -Department of Optical Sciences, University of Arizona, Tucson, AZ 85721, United States. orcid.org/0000-0002-9853-3678.

Vanessa Huxter - Department of Chemistry and Department of Physics, University of Arizona, Tucson, AZ 85721, United States. orcid.org/0000-0001-9692-531.

\section{Author Contributions:}

T.L.G. conceived the idea and directed the project. A.C.S. performed the synthesis of the photocatalysts, their characterizations, and the mechanistic studies. J.M. conducted the cyclic voltammetry and performed the synthesis of the helicene radical. A.C.S. performed the catalytic reaction condition optimizations and catalytic transformations. A.C.S., M.M.H., and R.K. synthesized the starting materials and characterized the catalytic products formed. A.K., B. T. and V.H. performed the TA and lifetime measurements. A.C.S. and T.L.G. prepared the manuscript for publication. All authors have given approval to the final version of the manuscript.

\section{Notes:}

The authors declare no competing financial interest.

\section{ACKNOWLEDGMENTS}

We are grateful for financial support from the University of Arizona and the National Science Foundation under the CAREER award Grant No. 2144018 for this work. All NMR data were collected in the NMR facility of the Department of Chemistry and Biochemistry at the University of Arizona, and we thank Dr. Jixun Dai for his help. The purchase of the Bruker NEO $500 \mathrm{MHz}$ spectrometer was supported by the National Science Foundation under Grant No. 1920234 and the University of Arizona. We thank Dr. Andrei Astashkin (EPR facility of the University of Arizona) for performing the EPR measurements and helping with the analysis of the EPR spectra. We thank Arizona State University Core facilities for TCSPC studies. A. C. S. thanks the diversity and inclusion efforts from individuals, groups, and institutions towards a more united science community.

\section{REFERENCES}

(1) a) Bortolato, T.; Cuadros, S.; Simionato, G.; Dell'Amico, L.; The Advent and Development of Organophotoredox Catalysis. Chem. Commun., 2022, DOI: 10.1039/D1CC05850A. b) Stephenson, C. R. J.; Yoon, T. P.; MacMillan, D. W. C. Visible light photocatalysis in organic chemistry. Wiley-VCH Verlag, 2017, 444 p, DOI: 10.1002/9783527674145.

(2) a) Crisenza, G. E. M.; Melchiorre, P. Chemistry glows green with photoredox catalysis. Nat. Commun. 2020, 11, 803. b) McAtee, R. C.; McClain, E. J.; Stephenson, C. R. J. Illuminating Photoredox Catalysis. Trends in Chemistry 2019, 1, 111-125. c) Marzo, L.; Pagire, S. K.; Reiser, O.; König, B. Visible-Light Photocatalysis: Does It Make a Difference in Organic Synthesis? Angew. Chem., Int. Ed. 2018, 57, 10034-10072. d) Shaw, M. H.; Twilton, J.; MacMillan, D. W. C. Photoredox Catalysis in Organic Chemistry. J. Org. Chem. 2016, 81, 6898-6926. e) Romero, N. A.; Nicewicz, D. A. Organic Photoredox Catalysis. Chem. Rev. 2016, 116, 10075-10166. f) Prier, C. K.; Rankic, D. A.; MacMillan, D. W. C. Visible Light Photoredox Catalysis with Transition Metal Complexes: Applications in Organic Synthesis. Chem. Rev. 2013, 113, 5322-5363. g) Tucker, J. W.; Stephenson, C. R. J. Shining Light on Photoredox Catalysis: Theory and Synthetic Applications. J. Org. Chem. 2012, 77, 1617-1622.

(3) Reviews: a) Novaes, L. F. T.; Liu, J.; Shen, Y.; Lu, L.; Meinhardt, J. M.; Lin, S. Electrocatalysis as an Enabling Technology for Organic Synthesis. Chem. Soc. Rev. 2021, 50, 7941-8002. b) Tay, N. E. S.; Lehnherr, D.; Rovis, T. Photons or Electrons? A Critical Comparison of Electrochemistry and Photoredox Catalysis for Organic Synthesis. Chem. Rev. 2021, DOI: 10.1021/acs.chemrev.1c00384. Selected articles: c) Shen, T.; Lambert, T. H. 
Electrophotocatalytic Diamination of Vicinal C-H Bonds. Science 2021, 371, 620-626. d) Kim, H.; Kim, H.; Lambert, T. H.; Lin, S. Reductive Electrophotocatalysis: Merging Electricity and Light to Achieve Extreme Reduction Potentials. J. Am. Chem. Soc. 2020, 142, 2087-2092. e) Cowper, N. G. W.; Chernowsky, C. P.; Williams, O. P.; Wickens, Z. K. Potent Reductants via Electron-Primed Photoredox Catalysis: Unlocking Aryl Chlorides for Radical Coupling. J. Am. Chem. Soc. 2020, 142, 2093-2099.

(4) a) Wu, S.; Kaur, J.; Karl, T. A.; Tian, X.; Barham, J. P. Synthetic Molecular Photoelectrochemistry: New Frontiers in Synthetic Applications, Mechanistic Insights and Scalability. Angew. Chem. Int. Ed., 2022, DOI:10.1002/anie.202107811. b) Glaser, F.; Kerzig, C.; Wenger, O. S. Multi-Photon Excitation in Photoredox Catalysis: Concepts, Applications, Methods. Angew. Chem. Int. Ed. 2020, 59, 10266-10284. c) Schmalzbauer, M.; Marcon, M.; König, B. Excited State Anions in Organic Transformations. Angew.Chem.Int.Ed. 2021, 60, 6270-6292. (5) Ghosh, I. Excited radical anions and excited anions in visible light photoredox catalysis. Physical Sciences Reviews, 2019, 4, 20170185.

(6) Other than the reductive ConPET, an oxidative ConPET was recently reported: Targos, K.; Williams, O. P.; Wickens, Z. K. Unveiling Potent Photooxidation Behavior of Catalytic Photoreductants. J. Am. Chem. Soc. 2021, 143, 4125-4132.

(7) a) Zeman, C. J.; Kim, S.; Zhang, F.; Schanze, K. S. Direct Observation of the Reduction of Aryl Halides by a Photoexcited Perylene Diimide Radical Anion. J. Am. Chem. Soc. 2020, 142, 2204-2207. b) Ghosh, I.; Ghosh, T.; Bardagi, J. I.; König, B. Reduction of aryl halides by consecutive visible light-induced electron transfer processes. Science 2014, 346, 725-728.

(8) Neumeier, M.; Sampedro, D.; Májek, M.; de la Peña O'Shea, V. A.; Jacobi von Wangelin, A.; Pérez-Ruiz, R. Dichromatic Photocatalytic Substitutions of Aryl Halides with a Small Organic Dye. Chem. - Eur. J. 2018, 24, 105-108.

(9) Bardagi, J. I.; Ghosh, I.; Schmalzbauer, M.; Ghosh, T.; König, B. Anthraquinones as Photoredox Catalysts for the Reductive Activation of Aryl Halides. Eur. J. Org. Chem. 2018, 2018, 34-40.

(10) a) Shaikh, R. S.; Düsel, S. J. S.; König, B. Visible-Light Photo-Arbuzov Re-action of Aryl Bromides and Trialkyl Phosphites Yielding Aryl Phos-phonates. ACS Catal. 2016, 6, 8410-8414. b) Ghosh, I.; König, B. Chromoselective Photocatalysis: Controlled Bond Activation through Light-Color Regulation of Redox Potentials. Angew. Chem., Int. Ed. 2016, 55, 7676-7679.

(11) Cole, J. P.; Chen, D.-F.; Kudisch, M.; Pearson, R. M.; Lim, C.-H.; Miyake, G. M. Organocatalyzed Birch Reduction Driven by Visible Light. J. Am. Chem. Soc. 2020, 142, 13573-13581.

(12) Chmiel, A. F.; Williams, O. P.; Chernowsky, C. P.; Yeung, C. S.; Wickens, Z. K. Non-innocent Radical Ion Intermediates in Photoredox Catalysis: Parallel Reduction Modes Enable Coupling of Diverse Aryl Chlorides. J. Am. Chem. Soc. 2021, 143, 10882-10889

(13) Xu, J.; Cao, J.; Wu, X.; Wang, H.; Yang, X.; Tang, X.; Toh, R. W.; Zhou, R.; Yeow, E. K. L.; Wu, J. Unveiling Extreme Photoreduction Potentials of Donor-Acceptor Cyanoarenes to Access Aryl Radicals from Aryl Chlorides. $J$. Am. Chem. Soc. 2021, 143, 13266-13273

(14) MacKenzie, I. A.; Wang, L.; Onuska, N. P. R.; Williams, O. F.; Begam, K.; Moran, A. M.; Dunietz, B. D.; Nicewicz, D. A. Discovery and Characterization of an Acridine Radical Photoreductant. Nature 2020, 580, 76-80.

(15) Graml, A.; Neveselý, T.; Jan Kutta, R.; Cibulka, R.; König, B. Deazaflavin reductive photocatalysis involves excited semiquinone radicals. Nat Commun. 2020, 11, 3174.

(16) Juliá, F.; Constantin, T.; Leonori, D. Applications of Halogen-Atom Transfer (XAT) for the Generation of Carbon Radicals in Synthetic Photochemistry and Photocatalysis. Chem. Rev. 2021, DOI: 10.1021/acs.chemrev.1c00558.

(17) a) Gorski, B.; Barthelemy, A.-L.; Douglas, J. J.; Julia, F.; Leonori, D. Copper-Catalysed Amination of Alkyl Iodides Enabled by Halogen-Atom Transfer. Nat. Catal. 2021, 4, 623-630. b) Constantin, T.; Zanini, M.; Regni, A.; Sheikh, N. S.; Juliá, F.; Leonori, D. Aminoalkyl radicals as halogen-atom transfer agents for activation of alkyl and aryl halides. Science 2020, 367, 1021-1026. c) Constantin, T.; Julia, F.; Sheikh, N. S.; Leonori, D. A Case of Chain Propagation: a-Aminoalkyl Radicals as Initiators for Aryl Radical Chemistry. Chem. Sci. 2020, 11, 12822-12828.

(18) Rieth, A. J.; Gonzalez, M. I.; Kudisch, B.; Nava, M.; Nocera, D. G. How Radical Are "Radical" Photocatalysts? A Closed-Shell Meisenheimer Complex Is Identified as a Super-Reducing Photoreagent. J. Am. Chem. Soc. 2021, 143, 14352-14359.

(19) a) Herse, C.; Bas, D.; Krebs, F.; Bürgi, T.; Weber, J.; Wesolowski, T.; Laursen, B.; Lacour, J. A Highly Configurationally Stable [4]Heterohelicenium Cation. Angew. Chem., Int. Ed., 2003, 42, 3162-3166. b) Laursen, B. W.; Krebs, F. C. Synthesis of a Triazatriangulenium Salt. Angew. Chem., Int. Ed., 2000, 39, 3432 -3434.

(20) a) Mei, L.; Gianetti, T. L. Helical Carbenium Ion-Based Organic Photoredox Catalyst: A Versatile and Sustainable Option in Red-Light-Induced Reactions. Synlett 2021, 32, 337-334. b) Mei, L.; Moutet, J.; Stull, S. M.; Gianetti, T. L. Synthesis of $\mathrm{CF}_{3}$-Containing Spirocyclic Indolines via a Red-Light Mediated 
Trifluoromethylation/Dearomatization Cascade. J. Org. Chem. 2021, 86, 15, 10640-10653. c) Stull, S. M.; Mei, L.; Gianetti, T. L. Red-Light-Induced ${ }^{n}$ Pr-DMQA ${ }^{+}$-Catalyzed [3+2] Cycloaddition of Cyclopropylamines with Alkenes or Alkynes. Syn. Lett. 2021, DOI: 10.1055/a-1665-9220. d) Mei, L.; Veleta, J. M.; Gianetti, T. L. Helical Carbenium Ion: A Versatile Organic Photoredox Catalyst in Red-Light-Mediated Reactions. J. Am. Chem. Soc. 2020, 142, 1205612061 .

(21) Shaikh, A. C; Moutet, J.; Veleta, J. M.; Hossain, M.; Bloch, J.; Astashkin, A. V.; Gianetti, T. L. Persistent, highly localized, and tunable [4] helicene radicals. Chem. Sci. 2020, 11, 11060-11067.

(22) Sørensen, T. J.; Nielsen, M. F.; Laursen, B. W. Synthesis and Stability of $N, N^{\prime}$-Dialkyl-1,13-dimethoxyquinacridinium (DMQA ${ }^{+}$: A [4]Helicene with Multiple Redox States. ChemPlusChem, 2014, 79, 1030-1035

(23) The ${ }^{n} \mathrm{Pr}-\mathrm{DMQA}^{\bullet}$ shows fluorescence lifetime $(\tau)=4.8 \mathrm{~ns}$ at $\lambda_{\text {exc }}=503 \mathrm{~nm}$ and $4.4 \mathrm{~ns}$ at $\lambda_{\text {exc }}=420 \mathrm{~nm}$. See supporting information for details.

(24) Our measured fluorescence lifetime of ${ }^{n} \mathrm{Pr}-\mathrm{DMQA}-\mathrm{BF}_{4}$ is consistent with the fluorescence lifetimes reported by Lacour et al. reported (5.5 ns, excitation at $470 \mathrm{~nm}$ ). Delgado, I. H.; Pascal, S.; Wallabregue, A.; Duwald, R.; Besnard, C.; Guénée, L.; Nançoz, C.; Vauthey, E.; Tovar, R. C.; Lunkley, J. L.; Muller, G.; Lacour, J. Functionalized Cationic [4]Helicenes with Unique Tuning of Absorption, Fluorescence and Chiroptical Properties up to the Far-Red Range. Chem. Sci. 2016, 7, 4685-4693.

(25) a) Angulo, G.; Rosspeintner, A. Bimolecular photo-induced electron transfer enlightened by diffusion. J. Chem. Phys. 2020, 153, 040902. b) Shields, B. J.; Kudisch, B.; Scholes, G. D.; Doyle, A. G. Long-Lived Charge-Transfer States of Nickel(II) Aryl Halide Complexes Facilitate Bimolecular Photoinduced Electron Transfer. J. Am. Chem. Soc. 2018, 140, 3035-3039.

(26) a) Conreaux, D.; Mehanna, N.; Herse, C.; Lacour, J. From Cationic to Anionic Helicenes: New Reactivity through Umpolung. J. Org. Chem. 2011, 76, 2716-2722. B) Guin, J.; Besnard, C.; Pattison, P.; Lacour, J. Highly selective additions of hydride and organolithium nucleophiles to helical carbenium ions. Chem. Sci. 2011, 2, 425-428.

(27) Bosson, J.; Labrador, G. M.; Besnard, C.; Jacquemin, D.; Lacour, J. Chiral Near-Infrared Fluorophores by SelfPromoted Oxidative Coupling of Cationic Helicenes with Amines/Enamines. Angew. Chem. Int. Ed. 2021, 60, 87338738.

(28) Enemærke, R. J.; Christensen, T. B.; Jensen, H.; Daasbjerg, K. Application of a new kinetic method in the investigation of cleavage reactions of haloaromatic radical anions. J. Chem. Soc., Perkin Trans. 2, 2001, 1620-1630 (29) a) Demmer, C. S.; Larsen, N. K.; Bunch, L. Review on modern advances of chemical methods for the introduction of a phosphonic acid group. Chem. Rev. 2011, 111, 7981-8006. b) Guga, P. P-chiral oligonucleotides in biological recognition processes. Curr. Top. Med. Chem. 2007, 7, 695-713. c) Moonen, K.; laureyn, I.; Stevens, C. V. Synthetic methods for azaheterocyclic phosphonates and their biological activity. Chem. Rev. 2004, 104, 6177-6216.

(30) Rossi-Ashton, J. A.; Clarke, A. K.; Unsworth, W. P.; Taylor, R. J. K. Phosphoranyl Radical Fragmentation Reactions Driven by Photoredox Catalysis. ACS Catal. 2020, 10, 7250-7261

(31) (a) Suzuki, A.; Brown, H. C. Organic Syntheses Via Boranes; Aldrich Chemical Company: Milwakee, 2003; Vol. 3. (b) Hall, D. G. Boronic Acids, 2nd ed.; Wiley-VCH: Weinheim, 2011. c) Ban, H. S.; Nakamura, H. Boron-Based Drug Design. Chem. Rec. 2015, 15, 616.

(32) Hao, Y.-J.; Hu, X.-S.; Zhou, Y.; Zhou, J.; Yu, J.-S. Catalytic Enantioselective $\alpha$-Arylation of Carbonyl Enolates and Related Compounds. ACS Catal. 2020, 10, 955-993.

(33) Johansson, C. C. C.; Colacot, T. J. Metal-Catalyzed $\alpha$-Arylation of Carbonyl and Related Molecules: Novel Trends in C-C Bond Formation by C-H Bond Functionalization. Angew. Chem. Int. Ed. 2010, 49, 676-707.

(34) Selected research articles: a) Zawodny, W.; Teskey, C. J.; Mishevska, M.; Völkl, M.; Maryasin, B.; González, L.; Maulide, N. $\alpha$-Functionalisation of ketones through metal-free electrophilic activation. Angew. Chem. Int. Ed. 2020, 59, 20935-20939. b) Li, J.; Bauer, A.; Di Mauro, G.; Maulide, N. $\alpha$-Arylation of carbonyl compounds through oxidative $\mathrm{C}-\mathrm{C}$ bond activation. Angew. Chem. Int. Ed. 2019, 58, 9816-9819. c) Jia, Z.; Gálvez, E.; Sebastián, R. M.; Pleixats, R.; Álvarez-Larena, Á.; Martin, E.; Vallribera, A.; Shafir, A. An alternative to the classical $\alpha$-arylation: the transfer of an intact 2-Iodoaryl from ArI(O2CCF3)2. Angew. Chem. Int. Ed. 2014, 53, 11298-11301. d) Xu, Q.-L.; Gao, H.; Yousufuddin, M.; Ess, D. H.; Kürti, L. Aerobic, transition-metal-free, direct, and regiospecific mono- $\alpha-$ arylation of ketones: synthesis and mechanism by DFT calculations. J. Am. Chem. Soc. 2013, 135, 14048-14051. e) Huang, X.; Maulide, N. Sulfoxide-mediated $\alpha$-arylation of carbonyl compounds. J. Am. Chem. Soc. 2011, 133, 85108513.

(35) Hossain, Md. M.; Shaikh, A. C; Moutet, J.; Gianetti, T. L. Photocatalytic $\alpha$-Arylation of cyclic ketones. Nature Synthesis, 2022, DOI: 10.1038/s44160-021-00021-0.

(36) Li, Y.; Wang, D.; Zhang, L.; Luo, S. Redox Property of Enamines. J. Org. Chem. 2019, 84, 12071-12090. 